3

6

\section{Photochemical Transformations of Carbon Dots in Aqueous Environments}

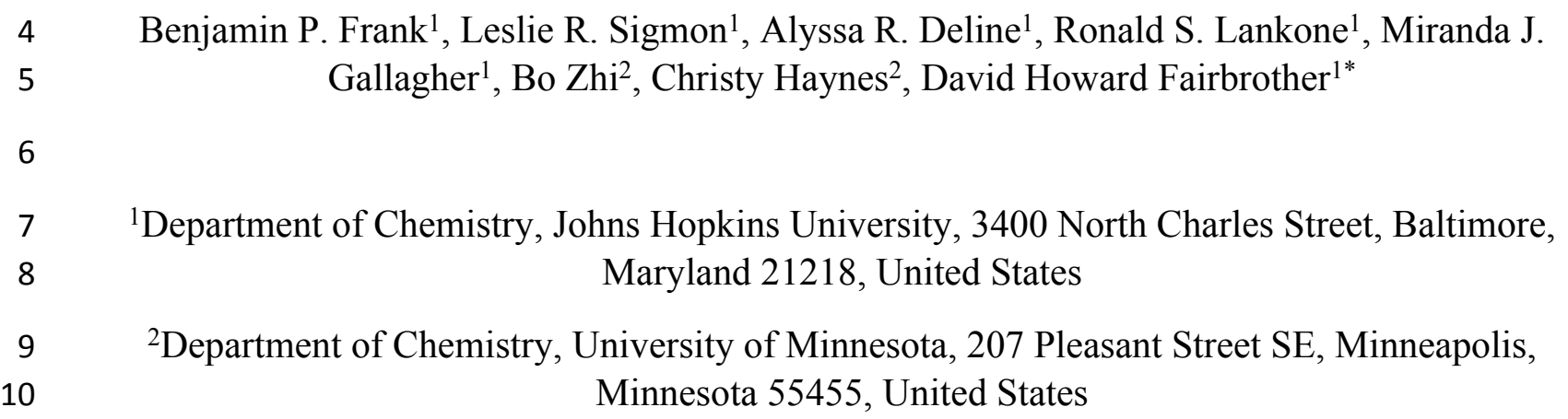
*Corresponding Author: D. Howard Fairbrother, Department of Chemistry, Johns Hopkins University, 3400 North Charles Street, Baltimore, Maryland 21218, United States
Email: howardf@jhu.edu

8

9




\section{Synthesis of CDs}

Carbon dots (CDs) were synthesized via bottom up microwave-assisted pyrolysis adapted from a previously reported method. ${ }^{1} 2 \mathrm{~mL}$ of a $4 \mathrm{M}$ citric or malic acid solution and $540 \mu \mathrm{L}$ of ethylenediamine were combined in a beaker, allowed to react (exothermic), and subsequently cooled at room temperature for $30 \mathrm{~min}$. The mixture was then heated in a microwave oven at $700 \mathrm{~W}$ for $2 \mathrm{~min}$. Approximately $10 \mathrm{~mL}$ of deionized water was added to the resultant solid and the mixture was magnetically stirred for $30 \mathrm{~min}$, or until it completely dissolved. Dialysis tubing (0.1-1.0 kDa pore size) was prepared by soaking in deionized water for $30 \mathrm{~min}$, before adding the dissolved CDs and dialyzing against deionized water for 24

h. The solution was transferred to an oven and dried at $40{ }^{\circ} \mathrm{C}$ until all water was evaporated and a redbrown solid remained.

\section{Characterization of CDs}

Transmission Electron Microscopy (TEM): TEM images of CACDs and MACDs were obtained using a FEI Tecnai F30 TEM with a $300 \mathrm{kV}$ electron beam.

UV-Visible Spectroscopy (UV-Vis): UV-visible extinction spectra were measured from 200 to $800 \mathrm{~nm}$ using a Thermo Scientific Evolution 220 UV-Visible spectrometer (Waltham, MA). CDs were analyzed at $15 \mathrm{mg} / \mathrm{L}$.

Photoluminescence (PL) Tests: Fluorescence (PL) spectra were obtained using a Thermo Scientific Lumina fluorescence spectrometer (Waltham, MA). An excitation wavelength of $350 \mathrm{~nm}$ was used and emission spectra were recorded from 360 to $650 \mathrm{~nm}$ with a $0.1 \mathrm{~nm}$ interval, a photomultiplier tube voltage of $700 \mathrm{~V}$, and a $20 \mathrm{~ms}$ integration time. Excitation and emission slit widths of $2.5 \mathrm{~nm}$ were used for CACD solutions and slit widths of $5 \mathrm{~nm}$ were used for MACD solutions. To avoid interference from inner filter effects, all CD solutions used in PL spectroscopy had absorbances of $\leq 0.1$ at the characteristic peak at approximately $350 \mathrm{~nm}$. CDs were analyzed at $15 \mathrm{mg} / \mathrm{L}$. 
51 Total carbon (TC)/Total Nitrogen (TN)/Ion Chromatography (IC) analysis: Solutions of $100 \mathrm{mg} / \mathrm{L}$

52 CACDs and MACDs were exposed to natural sunlight or ${ }^{\circ} \mathrm{OH}$. Test tubes wrapped in aluminum foil to

53 prevent light exposure were used as dark controls, and Milli-Q water samples were used as blank controls.

54 CD samples were diluted with Milli-Q water after photolysis to a volume of 20 or $40 \mathrm{~mL}$ for TC analysis.

55 Diluted samples were filtered through a $0.20 \mu \mathrm{m}$ PES syringe filter into acid-washed TC vials before

56 injection into a Shimadzu TOC-L total organic carbon analyzer equipped with a Shimadzu TNM-L total

57 nitrogen measuring unit and an ASI-L Shimadzu auto sampler (Kyoto, Japan). TC and TN signals were

58 converted into CD concentrations ( $\mathrm{mg} / \mathrm{L})$ via reference to calibration curves prepared with CDs. For TN,

59 the $\mathrm{CD}$ concentration was converted into $\mathrm{mg} \mathrm{N} / \mathrm{L}$ using a standard of sodium nitrate solution as a

60 reference. For IC, filtered samples prepared for TC/TN analysis were transferred into $0.5 \mathrm{~mL}$ vials and

61 analyzed with no further sample pre-treatment using Dionex ICS-2100 system (Thermo Fisher, Waltham,

62 MA) equipped with an AS18 ion exchange column. Samples were run using a $67 \mathrm{~mA}$ suppressor current

63 and $30 \mathrm{mM} \mathrm{KOH}$ eluent flow at a rate of $1 \mathrm{~mL} / \mathrm{min}$. A nitrate calibration curve was prepared from a

64 combined seven anion standard (Thermo Fisher, Waltham, MA).

65

66

67

68

69

70

71

72

73

74

75

Attenuated Total Reflectance Infrared (ATR-FTIR) spectra: Solutions of CACDs and MACDs were exposed to natural sunlight (at $2000 \mathrm{mg} / \mathrm{L}$ ) or ${ }^{\circ} \mathrm{OH}$ (at $350 \mathrm{mg} / \mathrm{L}$ ) and lyophilized (LabConco FreeZone 2.5 Plus, 2.5L, Kansas City, MO) into powders. ATR-FTIR of lyophilized CD samples were obtained using a Nicolet iS5 (Thermo Fisher, Waltham, MA) spectrometer with an iD5 ATR attachment using a scan range from $4000-525 \mathrm{~cm}^{-1}$ with 64 scans at $0.964 \mathrm{~cm}^{-1}$ resolution.

X-ray Photoelectron Spectroscopy (XPS): Solutions of CACDs and MACDs were exposed to natural sunlight (at $2000 \mathrm{mg} / \mathrm{L}$ ) or ${ }^{\circ} \mathrm{OH}$ (at $350 \mathrm{mg} / \mathrm{L}$ ) and lyophilized into powders. XPS of lyophilized CDs were obtained using a PHI (Chanhassen, MN) 5600 XPS equipped with a Mg K $\alpha$ flood source (1253.6 eV) and a hemispherical energy analyzer. High-resolution multiplex scans were collected at ultra-high vacuum $\left(8 \times 10^{-8}\right.$ torr $)$ with a source power of $300 \mathrm{~W}$, a pass energy of $29.35 \mathrm{eV}, 10$ sweeps per spectrum, and $0.125 \mathrm{eV} / \mathrm{step}$. Survey scans (1200-0 eV binding energy) were collected at the same ultra-high 
vacuum with a pass energy of $58.7 \mathrm{eV}, 2$ sweeps per spectrum, and $1.0 \mathrm{eV} / \mathrm{step}$. Spectra were analyzed

77 using CASA XPS software.

$78 N M R$ : For ${ }^{1} \mathrm{H}-\mathrm{NMR}$ analysis, $600 \mu \mathrm{L}$ of a $5 \mathrm{mg} / \mathrm{mL}$ solution of CACDs was exposed to natural sunlight

79 and analyzed in a NMR tube using a $400 \mathrm{MHz}$ NMR (Bruker UltraShield, Billerica, MA). For ${ }^{13} \mathrm{C}-\mathrm{NMR}$,

$80600 \mu \mathrm{L}$ of a $1.7 \times 10^{4} \mathrm{mg} / \mathrm{L}$ solution of photobleached CACDs exposed to ${ }^{\circ} \mathrm{OH}$ was analyzed using the

81 same spectrometer, run for 100 scans and 160 loops. Due to the higher concentration of CDs needed for

82 NMR $\left(1.7 \times 10^{4} \mathrm{mg} / \mathrm{L}\right.$ vs. $350 \mathrm{mg} / \mathrm{L}$ for ATR-FTIR/XPS data), a higher ${ }^{\circ} \mathrm{OH}$ dose was required to drop the

83 TC in solution to $40 \%$ of the initial concentration, allowing for the direct comparison between the

84 XPS/ATR-FTIR and NMR of the CDs. This amount of carbon loss required a ${ }^{\circ} \mathrm{OH}$ dose of $5.7 \times 10^{-8}$

$85 \mathrm{M}^{*} \mathrm{~min}$ and corresponded to the point in the carbon loss profile at the end of the first phase of degradation

86 by ${ }^{\circ} \mathrm{OH}$ (see Figure 3 ).

\section{Natural sunlight}

88 Photobleaching: CACD and MACD solutions with concentrations of $15 \mathrm{mg} / \mathrm{L}$ were prepared; solutions

89 wrapped in aluminum foil to prevent light exposure were used as dark controls. Samples were exposed to

90 natural sunlight and at time intervals of $0 \mathrm{~min}, 30 \mathrm{~min}, 1 \mathrm{~h}, 2 \mathrm{~h}$, and $12 \mathrm{~h}$, two irradiated CD samples

91 (light replicates) and a single dark control were removed. After removal, undiluted samples were analyzed

92 using UV-vis and PL spectroscopy.

93 Photobleaching Images: CACD and MACD solutions with concentrations of $100 \mathrm{mg} / \mathrm{L}$ were prepared

94 and exposed to natural sunlight for $0,30 \mathrm{~min}$, and 1, 4, 8, 12, 24, and $48 \mathrm{~h}$. After exposure, samples were

95 analyzed with UV-Vis and PL spectroscopy and images were taken under indoor or $350 \mathrm{~nm}$ light.

96 Photobleaching in Lab Light: CACD and MACD solutions with concentrations of $100 \mathrm{mg} / \mathrm{L}$ were

97 prepared and exposed to laboratory fluorescent lighting (emission spectrum in Figure S9b) for 10 days.

98 After exposure, samples were analyzed with PL spectroscopy. 
Effect of $\mathrm{O}_{2}$ and $\mathrm{N}_{2}$ Sparging: CACD and MACD solutions with concentrations of $15 \mathrm{mg} / \mathrm{L}$ were prepared

100

101

102

103

104

105

106

107

108

109

110

111

112

113

114

115

116

117

and either left untreated or were treated by bubbling with $\mathrm{N}_{2}$ or $\mathrm{O}_{2}$ for 15 minutes. Samples wrapped in aluminum foil to prevent light exposure were used as dark controls. Samples were exposed to natural sunlight at time intervals of $2 \mathrm{~min}, 4 \mathrm{~min}, 6 \mathrm{~min}, 10 \mathrm{~min}, 30 \mathrm{~min}, 1 \mathrm{~h}, 2 \mathrm{~h}, 4 \mathrm{~h}, 6 \mathrm{~h}$, and $24 \mathrm{~h}$. For each time interval, two irradiated CD samples (light replicates) and a single dark control were removed. After exposure, undiluted samples were analyzed using UV-visible and PL spectroscopy.

Aggregation/Settling Test: CACD and MACD solutions with CD concentrations of $15 \mathrm{mg} / \mathrm{L}$ were prepared and the $\mathrm{pH}$ was adjusted to 7 or 8 using $1 \mathrm{M} \mathrm{HCl}$ or $4 \mathrm{M} \mathrm{NaOH}$. For each type of $\mathrm{CD}$ at each $\mathrm{pH}$, four samples containing $8 \mathrm{~mL}$ each of CD solution were prepared. One irradiated sample and one dark sample had $\mathrm{NaCl}, \mathrm{KCl}$, and $\mathrm{CaCl}_{2}$ added to produce final salt concentrations of $15 \mathrm{mg} / \mathrm{L} \mathrm{NaCl}, 400 \mathrm{mg} / \mathrm{L}$ $\mathrm{KCl}$, and $400 \mathrm{mg} / \mathrm{L} \mathrm{CaCl}_{2}\left(4 \mathrm{mM} \mathrm{Ca}^{+2}, 13 \mathrm{mM} \mathrm{Cl}^{-}, 0.3 \mathrm{mM} \mathrm{Na}^{+}, 5 \mathrm{mM} \mathrm{K}\right.$ ). Blanks containing Milli-Q water with or without salts were also prepared. All samples were analyzed after 1 week of settling using PL spectroscopy.

TC and TN: Solutions of $100 \mathrm{mg} / \mathrm{L}$ CACDs and MACDs were exposed to natural sunlight for 0, 1, 2, 3, 4, 5, and 6 weeks. Samples were analyzed for TC and TN. Samples wrapped in aluminum foil were used as dark controls and Milli-Q water was used for blank controls.

ATR-FTIR and XPS: Solutions of $2000 \mathrm{mg} / \mathrm{L}$ CACDs and MACDs were exposed to natural sunlight for 2, 4, and 6 weeks and lyophilized (LabConco FreeZone 2.5 Plus, 2.5L, Kansas City, MO) into powders. ATR-FTIR and XPS were run on the recovered CD powder from each time point.

${ }^{1} H$-NMR: A $900 \mu \mathrm{L}$ sample of CACDs at $5 \mathrm{mg} / \mathrm{mL}$ in $\mathrm{D}_{2} \mathrm{O}$ was exposed to natural sunlight alongside an identical sample wrapped in aluminum foil to serve as a dark control. After $5 \mathrm{~d}$ of exposure, samples were retrieved from the roof and immediately transferred into an NMR tube for analysis.

Mass Recovery Experiments: A known mass of CACDs $(\sim 15 \mathrm{mg})$ was added to $6 \mathrm{~mL}$ of DI water and exposed in triplicate to natural sunlight for $21 \mathrm{~d}$ on a rooftop. Controls included an identical triplicate set 
of tubes wrapped in aluminum foil to serve as dark controls, and triplicate vials of pure DI water to serve as blanks. After $21 \mathrm{~d}$ of irradiation, the samples were lyophilized in pre-weighed centrifuge tubes and weighed using an analytical balance to determine the $\%$ recovery of CDs after natural sunlight exposure. It was determined that CACDs exposed to sunlight for $21 \mathrm{~d}$ yielded $101.4 \%+/-2.1 \%$ recovery, comparable to the dark control samples which were recovered at $95.8 \%+/-3.5 \%$, while, as expected, no mass was recovered from the blank controls. $\mathrm{pH}$ of these solutions was measured to be $\sim 7$ using litmus paper both before and after 21 days of exposure to natural sunlight.

\section{Exposure to ${ }^{\bullet} \mathrm{OH}$ Radicals}

CD solutions at $100 \mathrm{mg} / \mathrm{L}$ were placed into a Rayonet reactor and irradiated with $300 \mathrm{~nm}$ UV light (16 bulbs, RPR-300). Samples were dosed daily with $100 \mathrm{mM} \mathrm{H}_{2} \mathrm{O}_{2}$. UV-Vis was used to measure the loss of $\mathrm{H}_{2} \mathrm{O}_{2}$ over time and ensure that each dose of $\mathrm{H}_{2} \mathrm{O}_{2}$ was fully reacted before the next $\mathrm{H}_{2} \mathrm{O}_{2}$ dose was added.

TC/TN/IC: $10 \mathrm{~mL}$ samples at $100 \mathrm{mg} / \mathrm{L} \mathrm{CACD}$ and MACD were removed from the Rayonet after ${ }^{\circ} \mathrm{OH}$ doses up to $4.0 \times 10^{-8} \mathrm{M}^{*} \min$ and $2.8 \times 10^{-8} \mathrm{M}^{*} \min$, respectively. Samples wrapped in aluminum foil were used as dark controls and Milli-Q water was used as a blank control. Samples were analyzed using TC, TN, and IC.

ATR-FTIR and XPS: Samples for spectroscopic analysis were prepared at $350 \mathrm{mg} / \mathrm{L}$ CACDs or MACDs and exposed to ${ }^{\circ} \mathrm{OH}$ doses up to $1.1 \times 10^{-8} \mathrm{M}^{*}$ min before being lyophilized and compared to the unexposed parent CDs. Samples were analyzed using ATR-FTIR and XPS.

${ }^{13} \mathrm{C}$-NMR: CD samples for ${ }^{13} \mathrm{C}-\mathrm{NMR}$ were first photobleached at $1.7 \times 10^{4} \mathrm{mg} / \mathrm{L}$ and then reacted with an ${ }^{\circ} \mathrm{OH}$ dose of $5.7 \times 10^{-8} \mathrm{M}^{*} \min { }^{\bullet} \mathrm{OH}$. A ${ }^{13} \mathrm{C}-\mathrm{NMR}$ was then prepared at $1.7 \times 10^{4} \mathrm{mg} / \mathrm{L} \mathrm{CACD} / \mathrm{L} \mathrm{D}_{2} \mathrm{O}$ solution.

\section{Quantification of 'OH Radical Dose}


Procedures used here have been reported in greater detail by Lankone et al., ${ }^{2}$ In brief, salicylic acid (SA)

147 was used at $0.07 \mathrm{mM}$ as a probe molecule that could be quantified using UV-Vis spectroscopy. In the 148 presence of ${ }^{\circ} \mathrm{OH}$ radicals, SA reacts to form 2,3-dihydroxybenzoic acid and 2,5-dihydroxybenzoic acid.

149 Under irradiance with $300 \mathrm{~nm}$ light (in absence of ${ }^{\circ} \mathrm{OH}$ radicals), SA is photostable and decreases in 150 concentration by less than $4 \%$ over the 30 s necessary to perform the outlined measurements. To enable 151 deconvolution of SA from the two product species (2,3-dihydroxybenzoic acid and 2,5-dihydroxybenzoic 152 acid), reference solutions of each compound at a known concentration were prepared. UV-Vis spectra 153 were collected of these reference solutions and later used to determine the concentration of SA during $154 \cdot \mathrm{OH}$ exposure in solutions containing a mixture of SA, 2,3-dihydroxybenzoic acid and 2,5155 dihydroxybenzoic acid. Since the rate constant for the reaction of SA with ${ }^{\circ} \mathrm{OH}$ radicals is known $\left(5 \times 10^{9}\right.$ $156 \mathrm{M}^{-1} \mathrm{~s}^{-1}$ ), measuring the rate of SA degradation enabled the steady state ${ }^{\circ} \mathrm{OH}$ concentration to be 157 determined for a given dose of $\mathrm{H}_{2} \mathrm{O}_{2}$. Crucially, $\mathrm{CD}$ exposure to $\mathrm{H}_{2} \mathrm{O}_{2}$ in the present study was performed in the absence of SA, necessitating a correction factor be applied to the ${ }^{\circ} \mathrm{OH}$ radical concentration measured with SA (from Lankone et al.) to determine the actual ${ }^{\circ} \mathrm{OH}$ radical concentration present in solutions used to photolyze CDs in these experiments. As part of the present study, we evaluated the $161[\mathrm{OH}]_{\mathrm{ss}}$ in the presence of CDs to show that for the concentrations used $(1-319 \mathrm{mg} / \mathrm{L})$, the presence of 162 CDs did not have an impact on $\left[{ }^{\circ} \mathrm{OH}\right]_{\mathrm{ss}}($ Figure $\mathrm{S} 1)$.

$\mathrm{H}_{2} \mathrm{O}_{2}$ concentration in the quartz vessels was tracked over time using UV-Vis spectroscopy, 164 which, along with knowledge of the $\left[{ }^{\circ} \mathrm{OH}\right]_{\mathrm{ss}}$ throughout the decomposition of $\mathrm{H}_{2} \mathrm{O}_{2}$, allowed for the dose 165 of ${ }^{\bullet} \mathrm{OH}$ radicals for each experiment to be determined. Moreover, this dose could also be related to the 166 timescale in the environment which would deliver the equivalent ${ }^{\circ} \mathrm{OH}$ dose. For example, a single 100 $167 \mathrm{mM}$ dose of $\mathrm{H}_{2} \mathrm{O}_{2}$ results in an average steady state ${ }^{\circ} \mathrm{OH}$ radical concentration of $5.79 \times 10^{-12} \mathrm{M}^{*}$ min for a 168 total exposure time of approximately $8 \mathrm{~h}$. Environmental $\left[{ }^{\circ} \mathrm{OH}\right]_{\mathrm{ss}}$ values in surface waters have been 169 reported on the order of $10^{-15}-10^{-17} \mathrm{M} \cdot \cdot^{3-5}$ In a given month, then (assuming a maximum exposure to ${ }^{\circ} \mathrm{OH}$ at $17010^{-15} \mathrm{M}$ ), we can estimate the dose of ${ }^{\circ} \mathrm{OH}$ radicals delivered in the natural environment is the product of 
$171 \quad 10^{-15} \mathrm{M}$ and 21,600 min (i.e., minutes in a 30 day month, assuming $12 \mathrm{~h}$ of sunlight per day). Therefore,

172 cumulative exposure to ${ }^{\circ} \mathrm{OH}$ from a single $100 \mathrm{mM} \mathrm{H}_{2} \mathrm{O}_{2}$ dose across its degradation period (i.e., 8 hours

173 of $300 \mathrm{~nm}$ irradiation) can be estimated to be roughly 129 months of environmental ${ }^{\circ} \mathrm{OH}$ exposure. Table

$174 \mathrm{~S} 1$ summarizes the relationship between $\mathrm{H}_{2} \mathrm{O}_{2}$ dose and environmental timescale.

\begin{tabular}{|c|c|c|c|c|}
\hline Total $\mathrm{H}_{\mathbf{2}} \mathrm{O}_{\mathbf{2}}$ Dose $(\mathbf{m M})$ & Photolysis Time $(\mathbf{m i n})$ & ${ }^{\circ}$ OH Dose $\left(\mathbf{M}^{*} \mathbf{m i n}\right)$ & Minimum Environmental Timescale (Months) & Maximum Environmental Timescale (Months) \\
\hline 25 & 60 & $3.5 \mathrm{E}-10$ & 16 & 32 \\
\hline 50 & 120 & $6.9 \mathrm{E}-10$ & 48 & 3211 \\
\hline 75 & 180 & $1.0 \mathrm{E}-09$ & 64 & 4817 \\
\hline 100 & 240 & $1.4 \mathrm{E}-09$ & 257 & 6422 \\
\hline$(2 \mathrm{x}) 100$ & 960 & $5.5 \mathrm{E}-09$ & 385 & 25689 \\
\hline$(3 \mathrm{x}) 100$ & 1440 & $8.3 \mathrm{E}-09$ & 514 & 38533 \\
\hline$(4 \mathrm{x}) 100$ & 1920 & $1.1 \mathrm{E}-08$ & 51378 & \\
\hline
\end{tabular}

Table S1. Relationship between initial $\mathrm{H}_{2} \mathrm{O}_{2}$ concentration and photolysis time to $\mathrm{OH}$ dose. The range of environmental timescale for equivalent ${ }^{\circ} \mathrm{OH}$ exposure in natural surface waters is also indicated, with the minimum and maximum values determined assuming a steady state ${ }^{\circ} \mathrm{OH}$ concentration of $10^{-15} \mathrm{M}$ and $10^{-17} \mathrm{M}$, respectively. Hydrogen peroxide doses beyond $(2 \mathrm{x}) 100 \mathrm{mM}$ yielded a linear increase in both hydroxyl radical dose and equivalent environmental exposure.

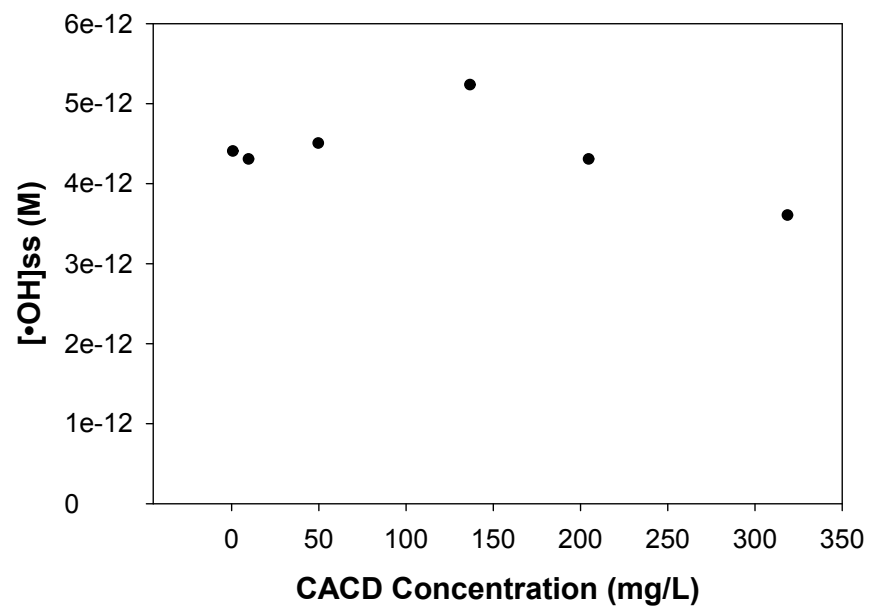

Figure S1. Steady state concentration of ${ }^{\circ} \mathrm{OH}\left(\left[{ }^{\circ} \mathrm{OH}\right]_{\mathrm{ss}}\right)$ generated by photolysis of $100 \mathrm{mM} \mathrm{H}_{2} \mathrm{O}_{2}$ in the presence of 1-319 $\mathrm{mg} / \mathrm{L}$ photobleached CACDs. 
a)

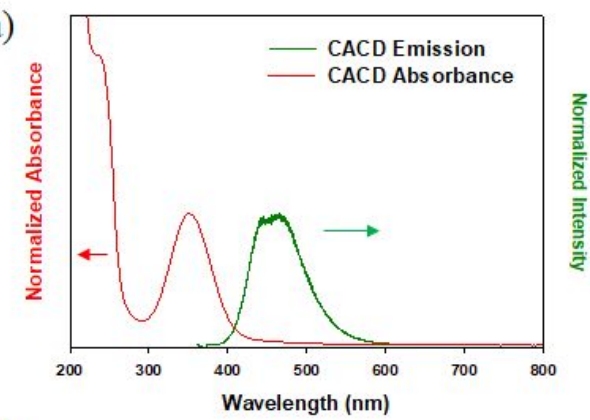

c)

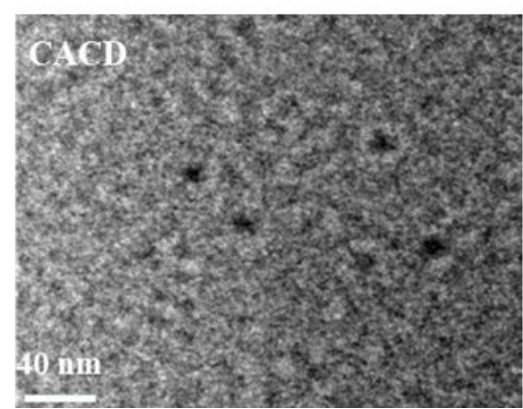

b)

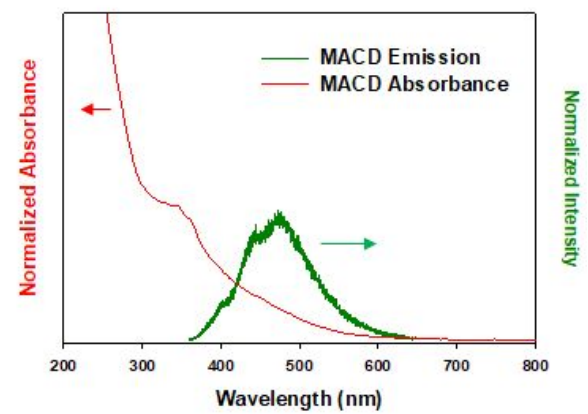

d)

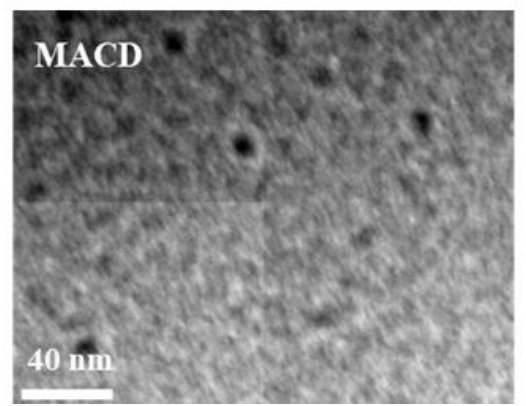

Figure S2. Characterization of parent CDs. Emission and absorption profiles of CACDs (a) and MACDs (b). Transmission electron microscopy of CACDs (c) and MACDs (d).

a)

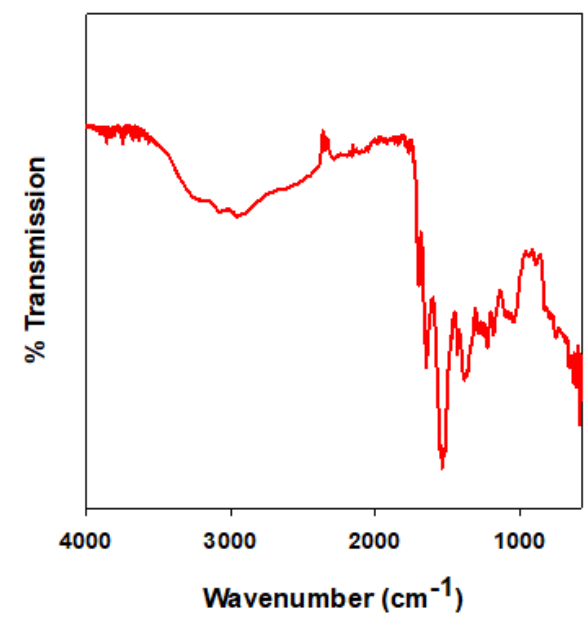

b)



Figure S3. ATR-FTIR spectra of lyophilized as-synthesized CACDs (a) and MACDs (b). 

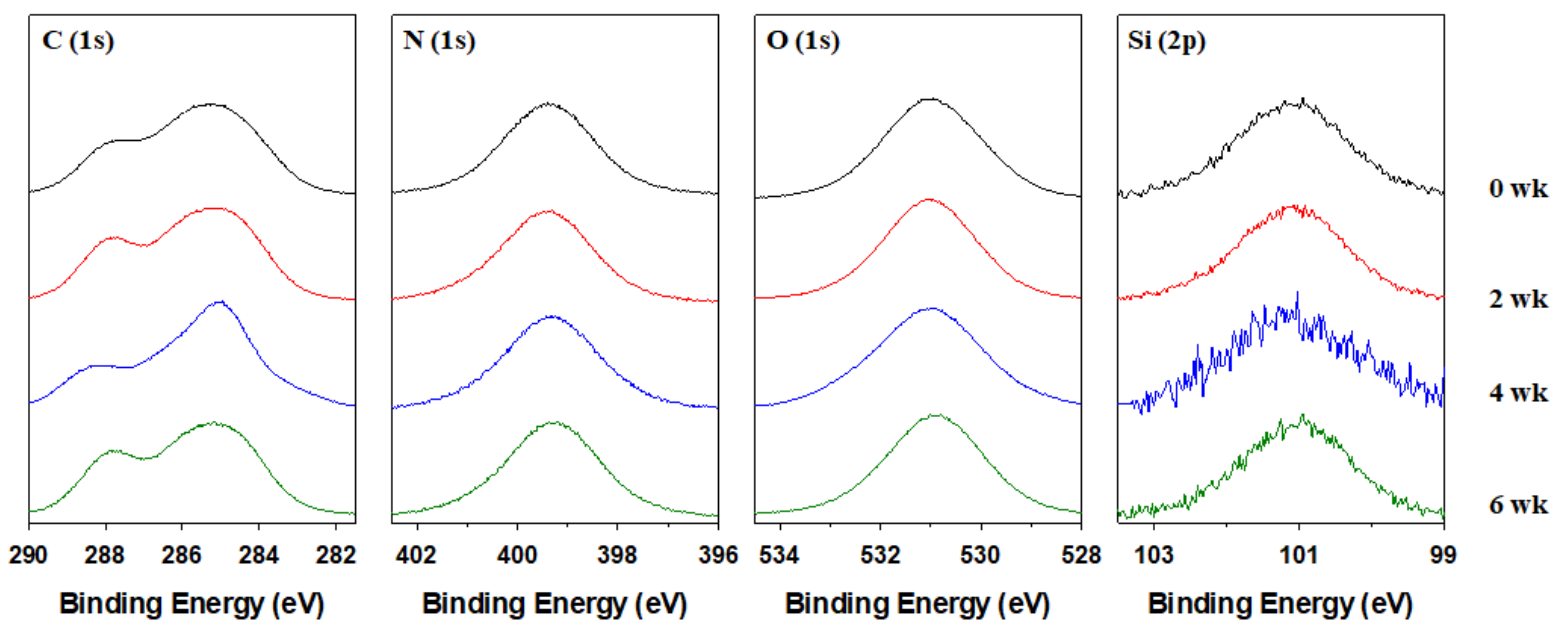

Figure S4. Normalized C (1s), N (1s), O (1s), and Si (2p) XPS regions of lyophilized CACDs after exposure to 0 (black), 2 (red), 4 (blue), and 6 (green) weeks of natural sunlight. Silicon is from $\mathrm{SiO}_{2}$, residual from $\mathrm{CD}$ synthesis.
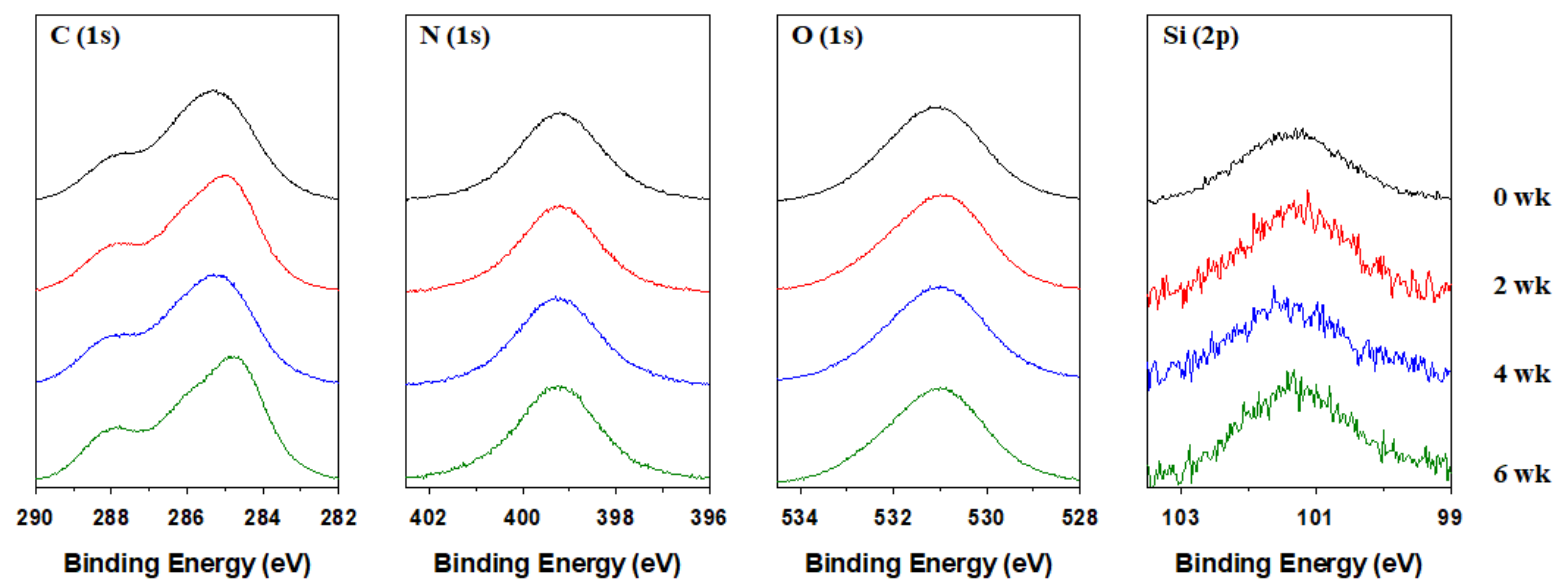

Figure S5. Normalized C (1s), N (1s), O (1s), and Si (2p) XPS regions of lyophilized MACDs after exposure to 0 (black), 2 (red), 4 (blue), and 6 (green) weeks of natural sunlight. Silicon is from $\mathrm{SiO}_{2}$, residual from $\mathrm{CD}$ synthesis. 

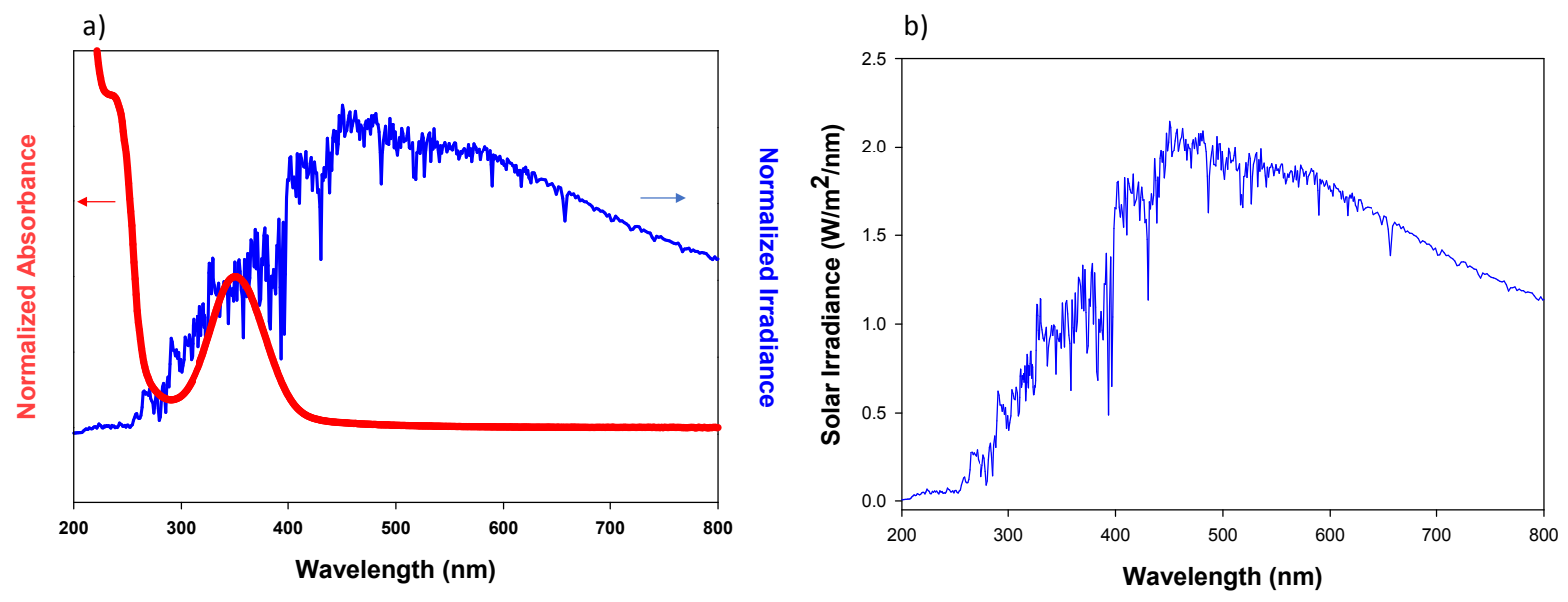

Figure S6. a) Absorption profile of CACDs (red) overlaid with the solar irradiance spectrum (blue, obtained from https://www.nrel.gov/grid/solar-resource/spectra-astm-e490.html). b) Solar irradiance spectrum with units.

190

191

192

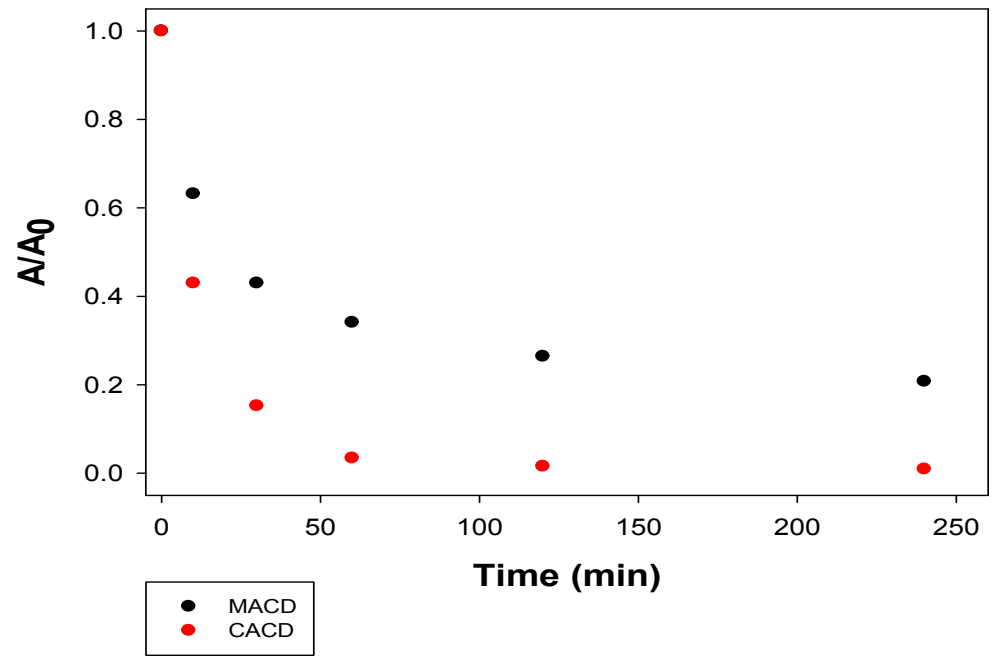

Figure S7. Photobleaching rates of $15 \mathrm{mg} / \mathrm{L} \mathrm{CACDs} \mathrm{(red)} \mathrm{or} \mathrm{MACDs} \mathrm{(black)} \mathrm{after} 240 \mathrm{~min}$ of natural sunlight exposure as measured by photoluminescence spectroscopy (PL). Fluorescence is shown in terms of the area of the emission curve at each time point normalized to the initial emission at $\mathrm{t}=0$. 
CACDs
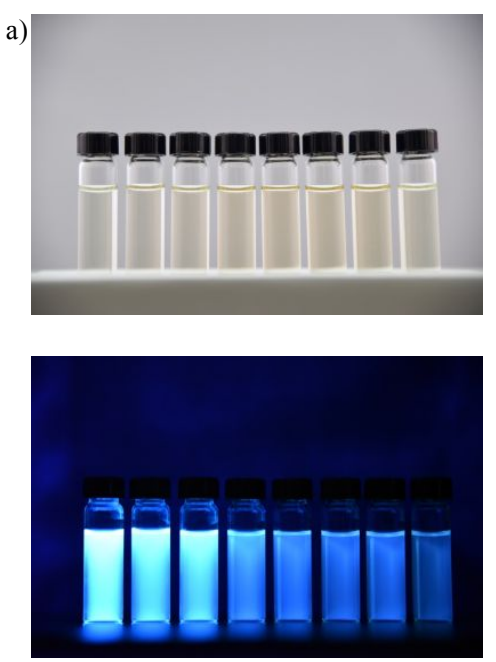

MACDs

b)
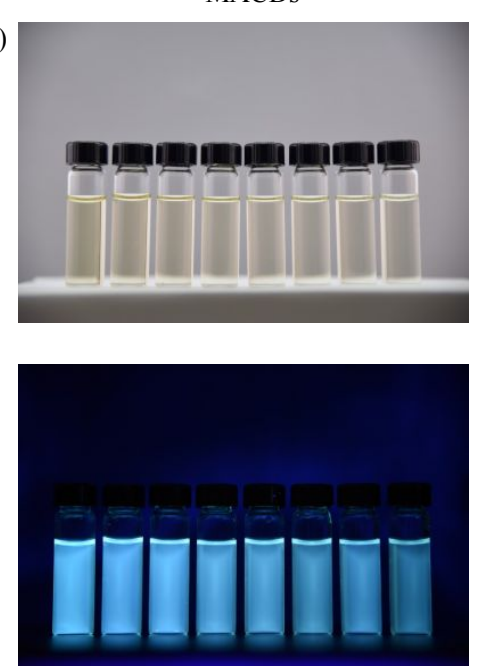

Figure S8. Photographs of $100 \mathrm{mg} / \mathrm{L}$ solutions of CACDs (a) and MACDs (b) after exposure to 0, 0.5, $1,4,8,12,24$, or $48 \mathrm{hr}$ (left to right) of sunlight. Samples are shown post-exposure under either lab light (top) or $350 \mathrm{~nm}$ light (bottom).

196

197 a)

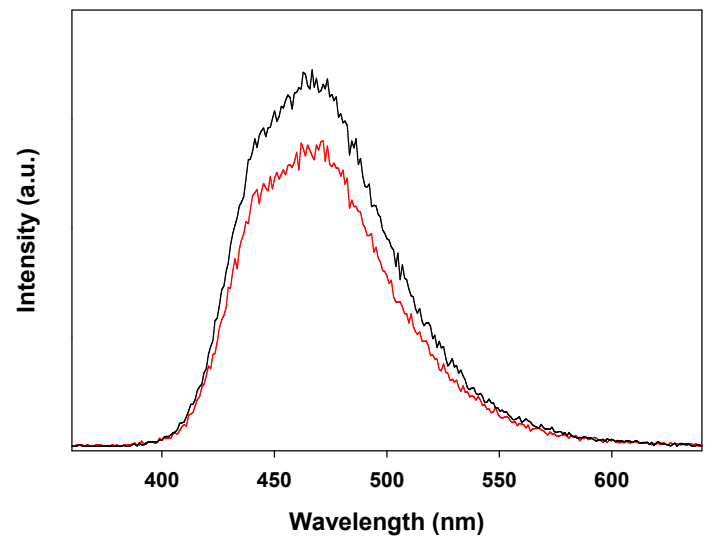

b)

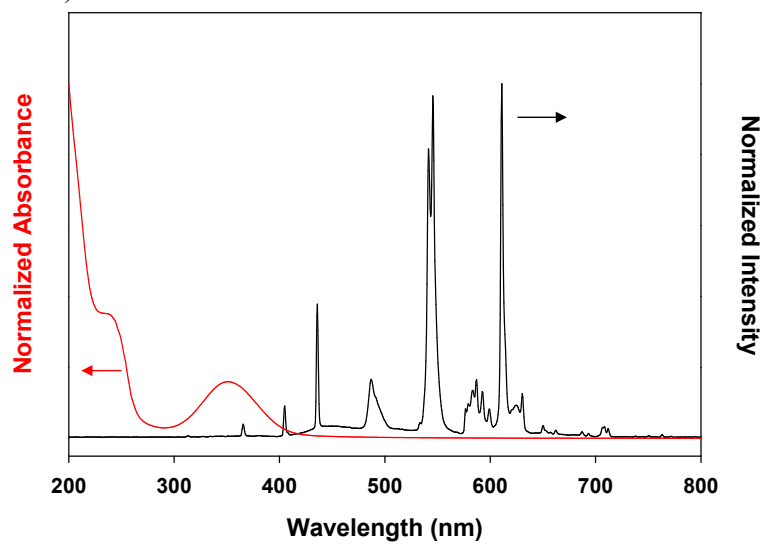

Figure S9. a) Photoluminescence spectra of CACDs before (black) and after (red) 10 days of laboratory fluorescent light exposure. b) Absorption profile of CACDs (red) overlaid with the emission spectrum of fluorescent indoor bulbs (black). CD concentration matched that used in natural sunlight exposures (i.e., $100 \mathrm{mg} / \mathrm{L}$ ). 


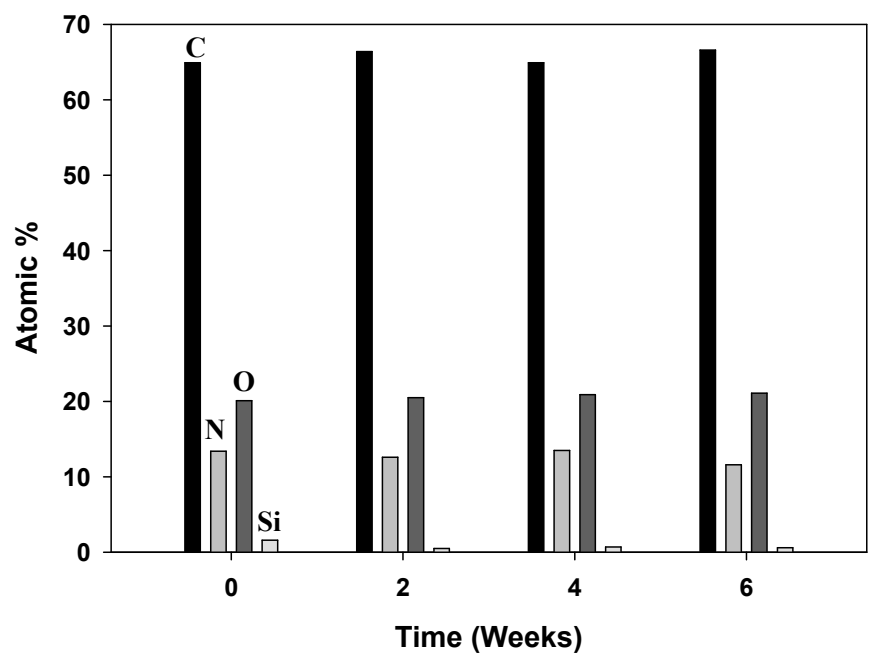

Figure S10. Atomic composition of lyophilized MACDs exposed to 0-6 weeks of natural sunlight as determined by XPS.

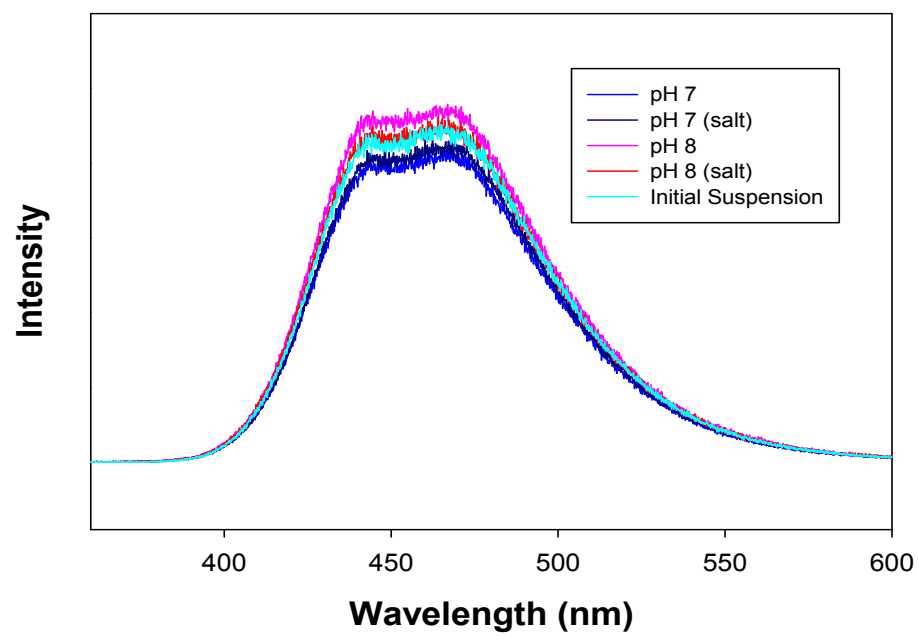

Figure S11. Photoluminescence spectroscopy of $15 \mathrm{mg} / \mathrm{L}$ CACD fluorescence before and after 1 week of settling at $\mathrm{pH} 7$ or 8 in pure water or in a mixture of $15 \mathrm{mg} / \mathrm{L} \mathrm{NaCl}, 400 \mathrm{mg} / \mathrm{L} \mathrm{KCl}$, and $400 \mathrm{mg} / \mathrm{L}$ $\mathrm{CaCl}_{2}\left(4 \mathrm{mM} \mathrm{Ca}^{+2}, 13 \mathrm{mM} \mathrm{Cl}^{-}, 0.3 \mathrm{mM} \mathrm{Na}^{+}, 5 \mathrm{mM} \mathrm{K}^{+}\right)$. 


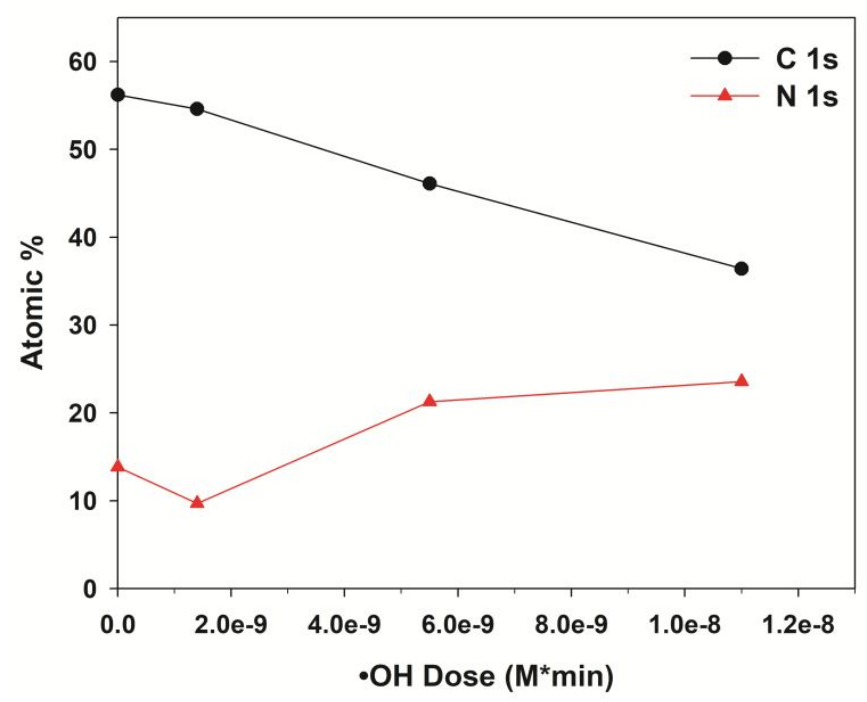

Figure S12. Atomic \% of carbon (black) and nitrogen (red) in lyophilized CACDs after exposure to a dose of $0-1.1 \times 10^{-8} \mathrm{M}^{*} \min { }^{\circ} \mathrm{OH}$ as determined with XPS.

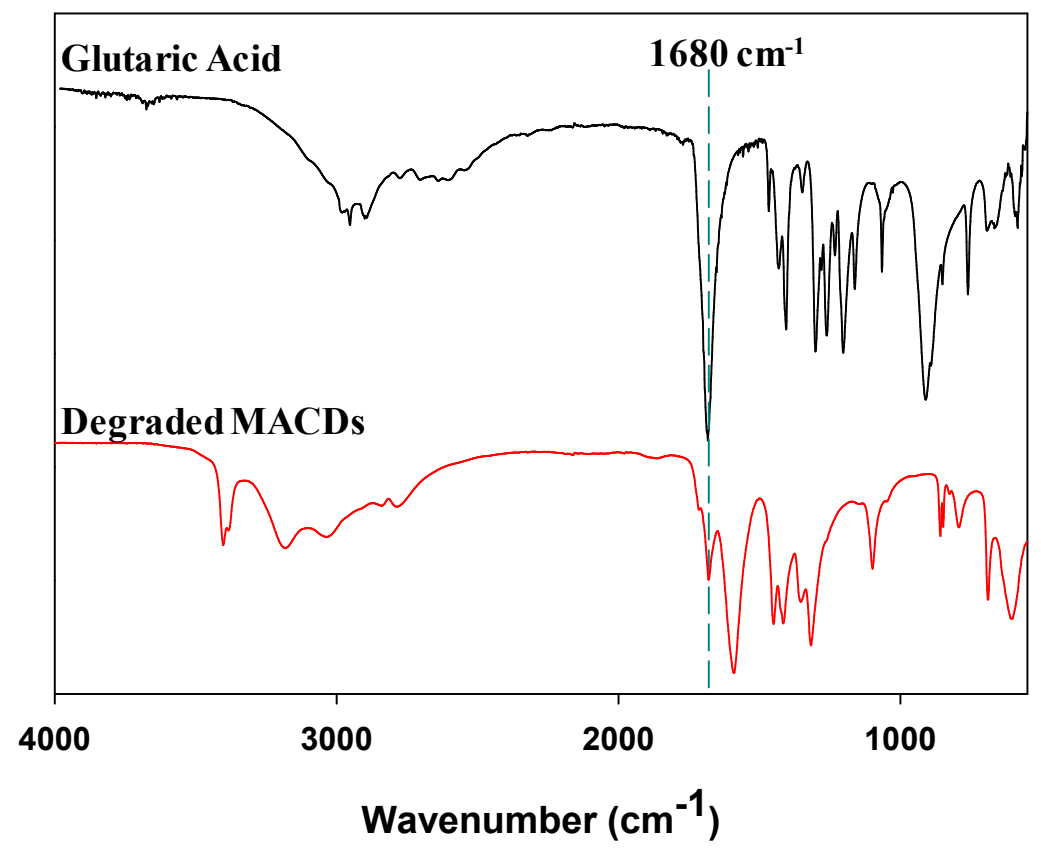

Figure S13. ATR-FTIR spectrum of glutaric acid (black) compared to lyophilized MACDs exposed to $5.5 \times 10^{-9} \mathrm{M}^{*} \min { }^{\circ} \mathrm{OH}(\mathrm{red})$. Dotted line at $1680 \mathrm{~cm}^{-1}$ marks the $\mathrm{C}=\mathrm{O}$ stretch of a carboxylic acid group. 
1. Zhi, B.; Gallagher, M. J.; Frank, B. P.; Lyons, T. Y.; Qiu, T. A.; Da, J.; Mensch, A. C.; Hamers, R. J.; Rosenzweig, Z.; Fairbrother, D. H.; Haynes, C. L., Investigation of phosphorous doping effects on polymeric carbon dots: fluorescence, photostability, and environmental impact. Carbon 2018, 129, 438449.

$221 \quad 2 . \quad$ Lankone, R. S.; Barclay, M.; Deline, A. R.; Fairbrother, D. H., Quantifying hydroxyl radical 222 concentrations and total dose via principle component analysis of UV-Vis Spectroscopy. Anal. Methods 223 Submitted.

$224 \quad 3 . \quad$ Hou, W.-C.; Henderson, W. M.; Chowdhury, I.; Goodwin, D. G.; Chang, X.; Martin, S.; Fairbrother, 225 D. H.; Bouchard, D.; Zepp, R. G., The contribution of indirect photolysis to the degradation of graphene oxide in sunlight. Carbon 2016, 110, 426-437.

4. Haag, W. R.; Hoigné, J., Photo-sensitized oxidation in natural water via .OH radicals. Chemosphere 1985, 14 (11), 1659-1671.

5. Page, S. E.; Logan, J. R.; Cory, R. M.; McNeill, K., Evidence for dissolved organic matter as the primary source and sink of photochemically produced hydroxyl radical in arctic surface waters. Environ. Sci. Proc. Imp. 2014, 16 (4), 807-822. 